\title{
Housing Choices and Their Implications for Consumption Heterogeneity
}

de Francisco, Eva

Please cite paper as:

de Francisco, Eva (2019). Housing Choices and Their

Implications for Consumption Heterogeneity. International

Finance Discussion Papers 1249.

https://doi.org/10.17016/IFDP.2019.1249

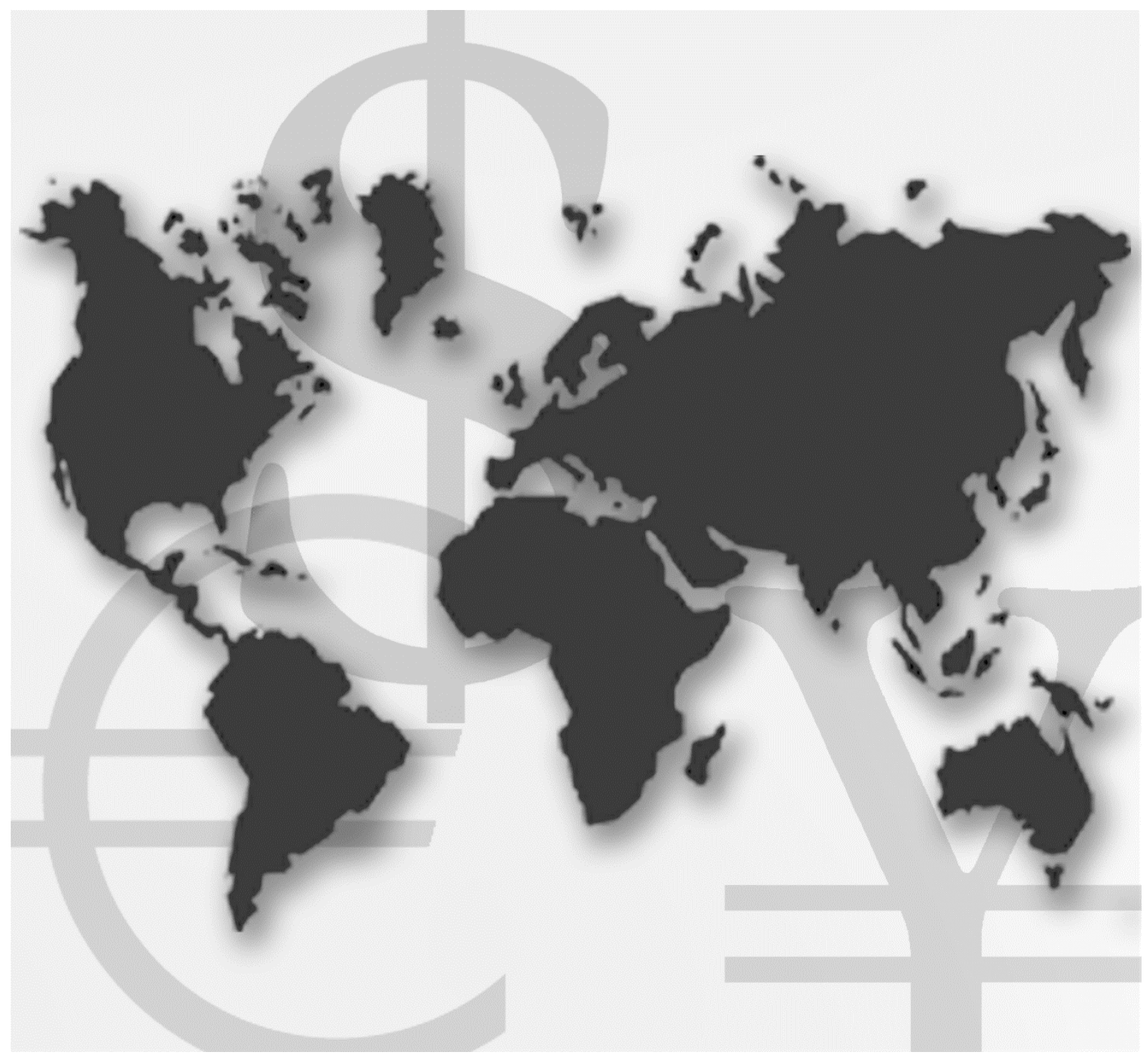

\section{International Finance Discussion Papers}

Board of Governors of the Federal Reserve System

Number 1249

May 2019 
Board of Governors of the Federal Reserve System

International Finance Discussion Papers

Number 1249

May 2019

\section{Housing Choices and Their Implications for Consumption Heterogeneity}

Eva de Francisco

NOTE: International Finance Discussion Papers are preliminary materials circulated to stimulate discussion and critical comment. References to International Finance Discussion Papers (other than an acknowledgment that the writer has had access to unpublished material) should be cleared with the author or authors. Recent IFDPs are available on the Web at www.federalreserve.gov/pubs/ifdp/. This paper can be downloaded without charge from the Social Science Research Network electronic library at www.ssrn.com. 


\title{
Housing choices and their implications for consumption heterogeneity*
}

\author{
Eva de Francisco ${ }^{\dagger}$
}

May 20, 2019

\begin{abstract}
This paper proposes a model to jointly explain some of the heterogeneous individual consumption behavior found in the recent empirical literature, such as the existence of a significant size of wealthy handto-mouth consumers, and negative marginal propensities to consume associated with housing upgrades. Agents live for a finite horizon, are heterogeneous in initial wealth, and can save in a liquid asset, and in an illiquid housing asset, that also provides housing services. When housing choices are very limited, the model replicates these empirical findings. Moreover, in the presence of unanticipated income shocks and endogenous credit constraints, this richness in marginal propensities to consume has significant implications for aggregate consumption, and helps explain the consumption behavior documented during the Great Recession as well as the consumption responses to recent tax rebates.
\end{abstract}

Keywords: The Great Recession, housing choices, consumption heterogeneity, wealthy hand-to-mouth consumers

JEL classifications: E13, E21, E62, C61, R21

${ }^{*}$ The views in this paper are solely the responsibility of the author and should not be interpreted as reflecting the views of the Board of Governors of the Federal Reserve System. I want to thank Samuel Bailey, who participated in earlier versions of this paper, seminar participants at the International Finance Division Research Seminar series at the Board of Governors, the Institute for Capacity Development at the International Monetary Fund, Towson University, and the Bureau of Economic Analysis. I would also like to thank Tyler Powell for outstanding research assistance, and the Congressional Budget Office for supporting my work in this paper during my tenure there.

${ }^{\dagger}$ Federal Reserve Board. e-mail: eva.defrancisco@frb.gov 


\section{Introduction}

Recent data on consumers finances have highlighted the existence of consumers with little or no liquid wealth who nonetheless own sizable illiquid assets (retirement accounts, college funds, real estate, and others), and that are important at explaining the 2001 and 2008 consumption responses to the fiscal rebates handed out those years. The literature has defined these individuals as wealthy hand-to-mouth consumers.

At the same time, data during the Great Recession shows that a large fraction of low-wealth households increased their savings as the recession hit the economy. Mechanical and even most types of endogenous wealthy handto-mouth consumers cannot generate this behavior as income and savings tend to move in the same direction.

And lastly, empirical evidence also suggests that households planning to upgrade or that recently upgraded their housing stock, cut nondurable consumption in the presence of positive income shocks, exhibiting negative marginal propensities to consume.

In this paper, I provide an explanation to account simultaneously for these facts.

The main contributions of this paper are the following. Adding a limited housing decision to a standard life cycle model generates a significant amount of wealthy hand-to-mouth consumers, as well consumers that exhibit negative marginal propensities to consume associated with adjustments in the stock of housing. These two results together can jointly explain some of the consumption behavior observed in the data in the last twenty years.

The explanation for the findings in this paper lies in the discrete nature of the home ownership decision-specifically on two features affecting this decision. First, the houses available in the market are just a few, very different from one another, and are also very lumpy with sizable transaction costs of moving from one house to another. And second, credit limits are endogenous, and buying a house usually requires an initial large down payment. Because of these features, becoming an owner and moving up to a bigger house requires significant initial savings, and then prompts consumers to optimally decrease non-durable consumption in the presence of large positive income shocks to upgrade the housing stock sooner rather than later. Once an agent has become a homeowner, because of transaction costs, adjusting the stock of housing, even when moving down to a cheaper house, is costly, so agents try to avoid this option in the presence of small shocks, and adjust nondurable consumption instead. However, because houses act as collateral,

only adjustments in the stock of housing allow individuals to change their 
savings rates drastically without changing nondurable consumption significantly too. In summary, this paper points out how a fragmented housing market structure is key for consumption dynamics.

Moreover, even though this paper abstracts from macroeconomic shocks, its findings contribute to the literature that studies how important heterogeneity at the household level may be for the amplification and propagation of macroeconomic shocks and provides an additional channel through the housing decision.

Home ownership has a dual role. On the one hand, it is an asset used by households to save for the long run, and on the other, it is a means of providing housing services. As assets, houses are also unique since they can act as collateral for mortgages.

As reported by the Survey of Consumer Finances (SCF), the increase in home ownership from $48 \%$ after World War II to almost $70 \%$ before the Great Recession constituted a very significant change in the composition of households balance sheets, and still remains high today by historical standards. Many papers have tried to explain the increase in home ownership.

Moreover, data show that for most American households, their primary house is also the most valuable asset in their portfolio. For example, in 2016 the SCF calculated that the conditional median value of a family house was $\$ 185,000$, more than 3 times the conditional median value of retirement accounts, the most popular financial asset used as a long term investment, underlying the increase in the popularity of houses as a vehicle for saving.

Houses are very lumpy and illiquid in nature and usually households require an initial, large, down payment to buy them. Because of these features, SCF data shows that most households needs time to save before they move out of renting into home ownership, and the biggest increase in home ownership rates happens between ages 30 and 40. Moreover, differences in home ownership rates by age are quite persistent through time, so adjustments in the housing stock are not very frequent. For example, in 2007, the U.S. Census Bureau estimated that a typical American will move only about 3 times after age 40, and wealthier individuals will move even less ${ }^{1}$.

This paper is organized as follows. Section 2 discusses how this paper contributes to the literature. Section 3 describes a very simple overlapping generation model with a very stylized housing choice. Section 4 shows the main results and the intuition and assumptions behind them. And finally, Section 5 concludes.

\footnotetext{
${ }^{1}$ In 2013, also using U.S. Census Bureau data, www.fivethirtyeight.com obtained similar results.
} 


\section{Literature Review}

This paper contributes to the literature by proposing a model that is capable of replicating some of the most salient individual consumption found in the empirical literature and is consistent with the cross section consumption data documented during the Great Recession.

In my model there is no uncertainty, the interest rates on debt and savings are the same, and buying a house expands access to credit as houses serve as collateral. Agents close to some income thresholds, can cut current consumption because doing so will allow them to expand their credit and move to a more desired housing sooner. Agents try to smooth the consumption of non-durables and durables over time using endogenous credit constraints to their advantage, and minimizing the amount of times they switch housing through their lifetime, reducing costly transaction costs along the way.

The theoretical model in this paper is similar to Gross $^{2}$ (2018), although as opposed to Gross, the existence of negative marginal propensities to consume, does not rely on idiosyncratic uncertainty. Using data from the Panel of Survey of Income Dynamics (PSID), Gross looks at how positive income shocks affect non-durable consumption when households have recently moved or are planning to move to a bigger house in the following two years and finds that these households exhibit negative propensities to consume $^{3}$. In his paper, agents are subject to idiosyncratic labor income risk, and have to pay a higher interest rate on their debt than the one they would receive on their savings. Therefore, in order to reduce the probability of hitting their borrowing constraint in the presence of a negative income shock, agents lower their level of consumption before and immediately after buying a house.

Moreover, this paper contributes to the literature that studies how individual consumption heterogeneity can have important consequences for aggregate consumption and for the multiplier effects of different fiscal policies.

Kaplan and Violante (2014) quantified the amount of wealthy hand-tomouth consumers in the U.S. using data from the 2001 SCF wave. The authors classified households by their liquidilliquid combinations of asset holdings and documented that around a $1 / 3$ of households in their sample

\footnotetext{
${ }^{2}$ Martin (2003) also found negative marginal propensities on food spending associated with housing moves.

${ }^{3}$ Look at the Appendix Subsection 6.1, Figures 5 and 6 for an extensive explanation of empirical results.
} 
fit the wealthy hand-to-mouth profile. A growing empirical literature, such as Kaplan and Violante (2014), Parker, Souleles, Johnson, and McClelland (2013), and others, has measured the consumption responses to the tax rebates handed out in the 2001 and 2008 recessions, finding that on average, households spent $25 \%$ of these rebates on non-durable consumption in the same quarter they received them. The authors pointed out convincingly that the $10 \%$ of truly constrained households usually found in the data is not enough to generate these high responses ${ }^{4}$.

Kaplan and Violante (2014) calibrated their model to the U.S. economy and found average marginal propensities to consume out of the tax rebates of 2001 between $11 \%$ and $25 \%$, depending on whether households knew the rebate was coming a quarter before they actually received it, or whether they were surprised by it.

Kaplan and Violante (2014), as most of the literature generating wealthy hand-to-mouth consumers endogenously, rely on assuming higher returns and transaction costs from investing in illiquid assets. In their setup, wealthy hand-to-mouth consumers are better off letting consumption fluctuate with income, as smoothing income shocks requires paying transaction costs to access their illiquid assets, holding cash and foregoing high returns, or tapping into expensive credit lines. Campbell and Hercowitz (2018) were an exception, assuming that periodically, households discover that they will have a special consumption need in the future, and will start savings for it until the need materializes.

As Kaplan and Violante (2014), my model agrees with the data findings in Misra and Surico (2011), who estimated that the actual empirical distribution of consumption responses for the 2001 tax rebate was very heterogeneous, finding that $1 / 2$ of the population did not respond at all, and $1 / 5$ responded by spending over $50 \%$ of the rebate in consumption.

In my paper, the limited housing choices and the requirement of a down payment, together with the links between credit constraints and housing choices, are enough to generate wealthy hand-to-mouth consumers who put all their wealth into the down payment of a house. In that sense, their non-housing consumption behavior is similar to traditional hand-to-mouth consumers, and can help explain part of the consumption response to tax rebates found in the data.

Krueger, Mitman, and Perri (2016) use PSID data over the 2006-2010 period to investigate how individual households adjusted their consumptionsavings behavior during the U.S. Great Recession of 2007-2009. The authors

\footnotetext{
${ }^{4}$ See Kaplan and Violante (2014).
} 
document that the households in the lowest two net worth quintiles hold almost no wealth but are responsible for almost $24 \%$ of total consumption expenditures. Moreover, during the Great Recession, saving rates increased across the whole wealth distribution, but more so at the bottom, delaying the recovery of aggregate demand. Using cross-sectional moments in net worth, disposable income, and consumption, the authors then test different versions of the Krusell-Smith (1998) heterogeneous agents model against the data. They found that the model that best fits the data, is one populated by a lot of wealth-poor households whose consumption responds strongly to the aggregate shock.

To explain the data, Krueger, Mitman, and Perri (2016) propose a model where precautionary savings against elevated unemployment risk increases a lot during a recession. For that to happen, agents need to be surprised not only by the size of the shock, but also by its persistence. The authors also investigate how social insurance programs affect the strength of this channel.

My paper can generate hand-to-mouth consumers whose income goes fully to pay the rent of a small apartment, and to non-durable consumption, and for whom a negative income shock reduces non-durable consumption one-to-one with income. But more importantly, the model generates wealth-poor households that respond to a negative income shock by increasing savings, as Krueger, Mitman, and Perri (2016) found in the data. In my model, these are low-wealth consumers, with no liquid wealth whose illiquid wealth is completely invested in the minimum down payment they put in a medium or large-sized house. In the presence of a negative income shock, some of these agents remain in their houses and drastically reduce non-durable consumption one-to-one with income, but other agents increase their savings by downsizing their housing stock, and reducing total consumption more than the drop in income. For these agents, nondurable consumption can increase or decrease; however, even when it increases, the decrease in durable consumption is larger than the increase in nondurable consumption, so aggregate consumption falls more than income, and savings increase.

Krueger, Mittman, and Perri (2016) rightly point out that in the majority of the models that generate wealthy hand-to-mouth consumers, these consumers endogenously choose to behave like traditional hand-to-mouth consumers, despite having some positive illiquid net worth. The reason is that because these assets are costly to liquidate, these agents do not change their savings rates for income shocks of moderate magnitude. However, the nature of an owner-occupied house and other illiquid assets such as 
tax-favored college funds or retirement accounts is quite different. In the presence of a negative income shock, it is easy to modify contributions to college funds or retirement accounts without incurring penalties. Mortgages payments, on the other hand, are usually fixed in the short run, so it is plausible that in the presence of the combined wealth and income shocks like the ones observed in the Great Recession, some wealthy hand-to-mouth consumers increased savings even without downsizing their house and taking up a smaller mortgage. If consumers perceived harder times ahead of them, they could increase savings as a precaution, just to be able to make mortgage payments in the future.

And lastly, my paper agrees with the empirical literature that finds that, unlike in previous recessions, the Great Recession was characterized by a fall in almost all components of consumption expenditures, not just durable expenditures. In this model, both, hand-to-mouth and wealthy hand-tomouth consumers can adjust non-durable consumption strongly. The reason is that, for most households, adjusting durable consumption is very costly, and consequently, households will try to adjust nondurable consumption first.

Mian, Rao, and Sufi (2013), and Kaplan, Mittman, and Violante (2016) find that the elasticity of non-durable expenditures to housing net worth during the Great Recession was between 0.24 and 0.36 . The authors classify geographical areas by the degree of decline of local housing prices, and find that this relationship is strongest in areas that experienced the smallest declines in housing net worth. Among areas with large housing prices declines, they find that the relationship between spending in nondurables and housing net worth is not significant. This is consistent with the model proposed in this paper, where big shocks that are more likely to prompt adjustments in the housing stock, have an indeterminate sign in the change of nondurable consumption.

Most of the recent housing literature has focused on explaining and matching home ownership rates across age and wealth distributions, looking at mortgage instruments or using different types of heterogeneity in preferences and a broad set of housing choices, effectively making housing choices almost continuous. For example, Chambers, Garriga, and Schlagenhauf (2009) decomposed the boom in home ownership from 1994 to 2005 into demographic changes and mortgage innovations using a quantitative general equilibrium model with housing. This paper will focus instead on the limited set of choices households really have, and how the unique collateral role of houses induces low-wealth individuals to become homeowners at 
the expense of hitting credit limits ${ }^{5}$.

There is a rich literature of partial equilibrium models trying to match some features of the housing demand we observe in the data. Notably, Attanasio, Botazzi, Low, Nesheim, and Wakefiled (2012), calibrate their models to the U.K. Similar to the rest of the literature ${ }^{6}$, these models use finer housing grids and assume utility functions that imply that owning a house gives agents a much higher higher utility than renting that same house. However, this assumption is hard to find in the data.

The literature using general equilibrium models with endogenous prices is more scarce, given the computational challenges involved. Rios-Rull and Sanchez-Marcos (2008) use an endowment economy with three assets-a tree, flats, and houses-to solve for prices in the stationary equilibrium. Their model is very stylized, but they calibrate it to the U.S. economy and are able to account for some characteristics of the total, financial, and housing wealth distribution relatively well. Iacoviello and Pavan (2013) look at housing and debt over the business cycle and solve a general equilibrium model with heterogeneity in preferences. Their model is calibrated to the U.S. economy and they match quite successfully wealth distribution, age profiles of home ownership and debt, and frequency of housing adjustment. This paper instead looks at a more fundamental motive for renting or buying a house, and examines what the effects of high home ownership rates for individual and aggregate consumption are.

Hatchondo, Martinez, and Sanchez (2015) introduce recourse mortgages in a life cycle model and calibrate it to the U.S. economy. They find that this prudential policy alone would not have been enough to prevent the increase in mortgage defaults observed since 2006. Although their paper does not look at nondurable consumption, it is clear from their setup, that if recourse mortgages were to become popular, we would also observe more significant decreases in nondurable consumption during recessions among households that default on their mortgage.

\footnotetext{
${ }^{5} \mathrm{~A}$ recent study by Lending Tree reported that current mortgage balances are around $68 \%$ of disposable income, while in 2008 , balances were above $90 \%$ of disposable income.

${ }^{6}$ Bajari, Chan, Krueger, and Miller (2013) estimate a partial equilibrium dynamic model of housing demand. Pizzinelli (2017) explores the interactions between housing, borrowing constraints, and labor supply over the life cycle, calibrating the model to the U.K. economy for the years 2001 to 2006.
} 


\section{Model}

In this section, I introduce a standard four-period overlapping generations model with no idiosyncratic or aggregate uncertainty of any kind, but with some important features highlighting the very different nature of the asset choices most households face -namely, the choice between a one-period liquid bond without transaction costs or lumpy initial investment requirements and a house.

Agents face a hump shaped earning profile throughout their life cycle and retire after period three, getting no labor income and no social security payments in their last period of life. They are forward looking, and in every period they choose non-durable consumption, how much to save in the liquid asset for the next period or how much to borrow, and whether to rent or buy a house to enjoy housing services this period. Houses are lumpy so, without loss of generality, there are only three discrete house choices agents can choose from: a small, medium, or large house. Moreover, since houses are an expensive and illiquid asset, if agents decide to buy a house, they need to put down a minimum down payment, and pay transaction costs, $\theta_{b}$ and $\theta_{s}{ }^{7}$.

In the model, both homeowners and renters can save in the liquid asset to obtain a rate of return on their savings, and they can also borrow some funds against their future labor income. Homeowners can borrow additional funds using their house as a collateral. Both the savings and the borrowing rate, $r$, are the same in the model.

\subsection{Environment}

Agents care about consumption and housing services, and their momentary utility is

$$
U(c, h)=\alpha_{c} \log (c)+\alpha_{h} \log (h)
$$

The type of house they choose affects their expenses and their access to credit markets; however contrary to most of the literature on housing, I purposely choose a utility function in which the flow of housing services consumers enjoy once they live in a house does not depend on whether they rent or buy the house, but only on the house's size. In this simple model, a house of size $\bar{h}$ provides housing services $\bar{h}$, no matter whether the house

\footnotetext{
${ }^{7}$ The literature estimates that there are transaction costs both when buying and when selling a house.
} 
is rented or bought. The relative share of non-durable consumption $\alpha_{c}$ and housing consumption $\alpha_{h}$ in the utility function, as well as the logarithmic utility function are common in the macro literature. The other feature worth noticing, which is different from the literature on housing, is that consistent with the data, this momentary utility does not assume that houses are a luxury good, as the value of the primary residence as a fraction of net worth is not increasing in net wealth ${ }^{8}$.

Consistent with the empirical literature, rented and owner occupied houses depreciate at different rates, $\delta_{r}$ and $\delta_{b}$ respectively ${ }^{9}$.

Survival at ages $i=1,2$, or 3 is $\psi_{i}=1$, and 0 at age 4 , so there is no mortality risk. I assume agents also care about the bequest they will leave to their offspring when they die. The bequest motive is captured by the function $B$ in equation (1) below. In all, agents have two motives to save, retirement and altruism.

Because of the discreetness of the housing set, together with the associated transaction costs from adjusting the stock of housing, the choice set is non-convex. To solve this type of problem, I apply the algorithm proposed by Fella (2014), which is more efficient and accurate than standard value function iterations algorithms. Following Fella, we need to first rewrite the budget constraint of agents. In the model, the budget constraint that agents face can be written as

$$
c+\omega^{\prime}+h+t\left(h^{-1}, h\right)=y+(1+r) \omega,
$$

where $c$ is non-durable consumption, $\omega$ is financial wealth at the beginning of the period, $h$ are expenditures in current housing services, $t\left(h^{-1}, h\right)$ is the cost of adjusting housing services from $h^{-1}$ in last period to $h$ this period, and $y$ is labor income.

Non-durable consumption is bounded below by a non-negativity constraint and above by a borrowing constraint as follows:

$$
\begin{aligned}
c & \geq 0 \\
\omega^{\prime} & \leq-\lambda y^{\prime}-\left(1-I_{\text {rent }}\right)(1-d) h
\end{aligned}
$$

where $\lambda$ is the portion of future labor income that can be borrowed, $d$ is the minimum down payment required when buying a house, and $I_{\text {rent }}$ is an

\footnotetext{
${ }^{8}$ For most SCF waves, the value of the primary residence as a fraction of net worth is decreasing in net wealth for the top $70 \%$ of the population.

${ }^{9}$ The depreciation rate of rental properties is much higher than the depreciation rate of residential structures.
} 
indicator function that takes the value of 1 when an agent chooses to rent in the current period.

If we call $\bar{m}_{c}(h)$ the maximum credit available for an agent choosing housing services $h$ this period, then we can define a' as the financial assets still available before hitting the credit limit the market offers when an agent's housing choice is $h$ as follows:

$$
\begin{aligned}
\bar{m}_{c}(h) & =\lambda y^{\prime}+\left(1-I_{\text {rent }}\right)(1-d) h \\
a^{\prime} & =\omega^{\prime}+\lambda y^{\prime}+\left(1-I_{\text {rent }}\right)(1-d) h \\
a^{\prime} & \geq 0
\end{aligned}
$$

Therefore, when $a^{\prime}=0$ we know that an agent is credit constrained. If the agent is a renter, then the agent is borrowing the maximum amount of uncollateralized debt possible (the highest fraction of future labor income allowed by markets), and if the agent is a homeowner, then the agent is borrowing the maximum amount of uncollateralized and collateralized debt possible, putting only the minimum down payment on a house.

When $a^{\prime} \geq 0$, if the agent is a renter, then we know the agent is investing in liquid assets. However, if the agent is a homeowner, the level of $a^{\prime}$ only tells us whether the agent is a net borrower or saver, as in the model the agent is indifferent between putting extra savings in the illiquid asset or in the liquid one, as the return on both is the same. In other words, the cost of borrowing is equal to the return on savings. Since credit lines against the equity of a house are very common and provide some liquidity, but are not as liquid as other assets, we will assume that when a homeowner is not credit constrained, some of her funds will be deposited in the liquid asset, and some will go toward a down payment beyond the minimum required.

Now we can rewrite a typical budget constraint in the model as

$$
c+a^{\prime}-\bar{m}_{c}(h)+h+t\left(h^{-1}, h\right)=y+(1+r)\left(a^{\prime}-\bar{m}_{c}\left(h^{-1}\right)\right) .
$$

In the model, housing services can be enjoyed renting a cheap or small apartment, so $h_{r}=h^{s}$, or buying two other more expensive options, this is, a medium or large size house, so $h_{b}=\left\{h^{m}, h^{l}\right\}$. In the paper the discussion among the housing options is framed in terms of the size of the house, but one can think more generally about housing services, so for example if we value a house because of the school district the house is located in, then the rental apartment in the model would be located in the worst school district, or if we value a house more or less depending on how far it is from a job or similar, then again the rental in the model would represent the house offering the longest commute and so on. The rental in the model is always 
the cheapest and most liquid option, but it is also the option that delivers less services since $h^{s}<h^{m}<h^{l}$.

In the model, every agent can enter the period as a nonhomeowner, or as a homeowner with state variable $a$.

\section{$3.2 \quad$ Nonhomeowner}

If an agent does not own a house, she can choose to remain a renter, or to buy a house. The lifetime utility of this agent is given by

$$
N_{i}(a)=\max _{I_{\text {rent }}=\{0,1\}}\left\{I_{\text {rent }} R_{i}(a)+\left(1-I_{\text {rent }}\right) B_{i}(a)\right\},
$$

where $R_{i}$ denotes the lifetime utility of a nonhomeowner of age $i$ who decides to continue to be a renter this period, and $B_{i}$ denotes the lifetime utility of a nonhomeowner of age $i$ who buys a house this period.

\section{$3.3 \quad$ Renter}

The value function of a renter of age $i R_{i}(a)$ is determined as follows:

$$
R_{i}(a)=\max _{c, a^{\prime}} U\left(c, h_{r}\right)+\beta\left\{\psi_{i} N_{i+1}(a)+\left(1-\psi_{i}\right) B\left(a^{\prime}\right)\right\}
$$

s.t.

$$
\begin{aligned}
c+a^{\prime}-\bar{m}_{c}\left(h_{r}\right)+r_{r} p_{r} h_{r} & =\frac{\left(a-\bar{m}_{c}\left(h_{r}\right)\right)}{\psi_{i-1}}(1+r)+y\left(e_{i}\right) \\
c & \geq 0 \\
a^{\prime} & \geq 0 \\
r_{r} & =r+\delta_{r},
\end{aligned}
$$

where $y\left(e_{i}\right)$ is labor income at age $i$, and $r_{r}$ is the rental rate per unit of housing. The return on assets or the cost of borrowing $r$ is exogenous, and given by $r=\frac{1}{\beta}-1$.

\subsection{Buyer}

The value function of a buyer of age $i B_{i}(a)$ is determined as follows:

$$
B_{i}(a)=\max _{c, a^{\prime}, h_{b}} U\left(c, h_{b}\right)+\beta\left\{\psi_{i} H_{i+1}(a)+\left(1-\psi_{i}\right) B\left(a^{\prime}\right)\right\}
$$


s.t.

$$
\begin{aligned}
c+p_{b} h_{b}\left(1+\theta_{b}\right)+a^{\prime}-\bar{m}_{c}\left(h_{b}\right) & =\frac{\left(a-\bar{m}_{c}\left(h_{r}\right)\right)}{\psi_{i-1}}(1+r)+y\left(e_{i}\right) \\
c & \geq 0 \\
a^{\prime} & \geq 0
\end{aligned}
$$

\subsection{Homeowner}

An agent that enters the period as a homeowner can (i) refinance her mortgage and stay in her house, or (ii) sell her house and buy another house or rent. We denote these two options as $\mathrm{F}$ and $\mathrm{S}$. Thus, the value function of a homeowner of age i $\left.H_{i}^{(} a\right)$ is given by:

$$
H_{i}(a)=\max _{I_{\text {ref }}=\{0,1\}, I_{\text {sell }}=\{0,1\}}\left\{I_{\text {ref }} R_{i}(a)+I_{\text {sell }} S_{i}(a)\right\}
$$

s.t.

$$
\begin{gathered}
I_{\text {ref }}+I_{\text {sell }}=1 \\
R_{i}(a)=\max _{a^{\prime}} U\left(c, h_{b}\right)+\beta\left\{\psi_{i} H_{i+1}\left(a^{\prime}\right)+\left(1-\psi_{i}\right) B\left(a^{\prime}\right)\right\}
\end{gathered}
$$

s.t.

$$
\begin{aligned}
c+a^{\prime}-\bar{m}_{c}\left(h_{b}\right)+\delta_{b} p_{b} h_{b} & =\frac{\left(a-\bar{m}_{c}\left(h_{b}\right)\right)}{\psi_{i-1}}(1+r)+y\left(e_{i}\right) \\
c & \geq 0 \\
a^{\prime} & \geq 0
\end{aligned}
$$

\subsection{Seller}

A seller can become a renter or buy another house as follows:

$$
\left.S_{i}(a)=\max _{I_{\text {rent }}=\{0,1}\right\}\left\{I_{\text {rent }} S_{i}^{R}(a)+\left(1-I_{\text {rent }}\right) S_{i}^{H}(a)\right\},
$$

where $S^{R}$ denotes the expected lifetime utility of selling a house and becoming a renter, and $S^{H}$ denotes the expected lifetime utility of selling a house and buying another house.

$S^{R}$ can be written as follows:

$$
S_{i}^{R}(a)=\max _{a^{\prime}} U\left(c, h_{r}\right)+\beta\left\{\psi_{i} R_{i+1}\left(a^{\prime}\right)+\left(1-\psi_{i}\right) B\left(a^{\prime}\right)\right\}
$$


s.t.

$$
\begin{aligned}
c+a^{\prime}-\bar{m}_{c}\left(h_{r}\right)-r_{r} p_{r} h_{r} & =\frac{\left(a-\bar{m}_{c}\left(h_{b}^{-1}\right)\right)}{\psi_{i-1}}(1+r)+y\left(e_{i}\right)+\left(1-\theta_{s}-\delta_{b}\right) p_{b} h_{b}^{-1} \\
c & \geq 0 \\
a^{\prime} & \geq 0,
\end{aligned}
$$

where $\theta_{s}$ is the transaction cost of selling a house.

Similarly, $S^{H}$ is represented by:

$$
S_{i}^{H}(a)=\max _{a^{\prime}, h_{b}} U\left(c, h_{b}\right)+\beta\left\{\psi_{i} H_{i+1}\left(a^{\prime}\right)+\left(1-\psi_{i}\right) B\left(a^{\prime}\right)\right\}
$$

s.t.

$$
\begin{aligned}
c+p_{b} h_{b}\left(1+\theta_{b}\right)+a^{\prime}-\bar{m}_{c}\left(h_{b}\right) & =\frac{\left(a-\bar{m}_{c}\left(h_{b}^{-1}\right)\right)}{\psi_{i-1}}(1+r)+y\left(e_{i}\right)+\left(1-\theta_{s}-\delta_{b}\right) p_{b} h_{b}^{-1} \\
c & \geq 0 \\
a^{\prime} & \geq 0
\end{aligned}
$$

In any theoretical model, the amount of housing choices as well as the distribution of the possible choices is key to matching aggregate rates of home ownership in the data. However, because the goal of this paper is to understand how the discreetness of the housing choices affects individual marginal propensities to consume, I will abstract from calibrating the grid of housing choices to match some particular moments in the data, and focus instead on the implications a discrete grid has on non-durable consumption, savings, and housing choices across the wealth distribution and over the life cycle.

\subsection{Partial Equilibrium Definition}

An equilibrium is characterized by (i) a set of value functions $N_{i}, R_{i}, B_{i}$, $H_{i}, S_{i}, S_{i}^{R}$, and $S_{i}^{B}$, (ii) a set of rules for nonhomeowners and sellers $I_{\text {rent }}$, and for homeowners $I_{r e f}$ and $I_{\text {sell }}$, and (iii) a set of choices a' and sizes of $h_{b}$, such that taking prices $p_{b}, p_{r}, r$, and $w$ as given, the set of rules and choices solve the value functions represented in equations (2), (3), (4), (5), (6), (7), and (8).

\section{Main Results}

In a model with endogenous borrowing constraints and transaction costs like this one, the marginal rate of substitution between consumption and housing 
services is not constant over time, making the model both interesting and difficult to solve at the same time.

Even though the following does not intend to be a calibration for the U.S. economy, I take the key parameter values in the model from the literature as shown in Table 1 and, using the endogenous grid method for non-smooth and non-concave problems proposed by Fella (2014), I solve for the partial equilibrium of the model for different housing and labor earnings grids such that the ratio of the median house value to labor income in the model is close to 2.8 as reported by Hatchondo, Martinez, and Sanchez (2015).

When $\left\{h^{s}, h^{m}, h^{l}\right\}=\{2,4,6\}$, this ratio can take values 3.6 or 2.7 depending on whether I take labor income in the first period of the model when agents are young, or or in the first two periods using an average of young and middle-aged agents.

Table 1: Parameters for the benchmark case

\begin{tabular}{lll}
\hline \hline Parameter & Definition & Basis \\
\hline$\delta_{r}=0.0749$ & Depreciation of rental property & Chambers et. al (2009) \\
$\delta_{b}=0.016$ & Depreciation of residential structures & Davis and Heathcote (2005) \\
$\theta_{s}=0.03$ & Cost of selling for households & Gruber and Martin (2003) \\
$\theta_{b}=0.06$ & Cost of buying for households & Standard in the literature \\
$\mathrm{d}=0.18$ & Minimum down payment & Hatchondo et. al (2015) \\
$\alpha_{c} / \alpha_{h}=2.7$ & Relative share in utility & Greenwood and Hercowitz (1991) \\
\hline
\end{tabular}

Figure 1 shows optimal choices for agents in their first period of life (young agents) depending on their initial wealth. Figure 1 shows that the discreteness of the housing choice is carried over to nondurable consumption, which now also presents some discrete jumps. Moreover, even controlling for age, nondurable consumption is not strictly increasing in wealth, and can decrease when an agent increases the stock of housing.

The available credit that remains after an agent chooses her level of saving or borrowing is represented by the red line in Figure 1. Agents with low wealth are credit constrained but hold positive wealth. All their wealth is saved in the down payment of a medium-sized house (the illiquid asset of the model) and therefore these agents fit the profile of a wealthy hand-tomouth consumer.

The discontinuities in non-durable consumption in Figure 1 are a consequence of the limited housing choices of the model, as well as the down payment requirement and credit available when an agent becomes a home- 
owner.

The jumps are robust to changes in the grid choices. The precise measure of the jumps in nondurable consumption is related to the distance between the points of the housing grid used for the numerical exercise, the transaction costs, and the minimum down payments.

\subsection{Wealthy hand-to-mouth consumers}

Figure 1: Real and financial choices of young agents when $h=\{2,4,6\}$

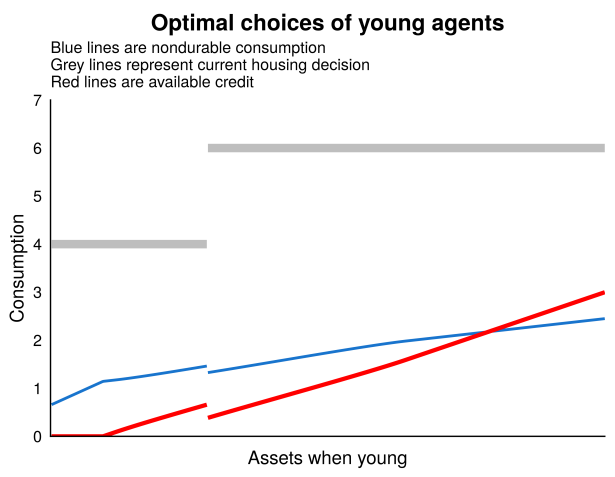

Benchmark economy

More interestingly, the model can generate wealthy hand-to-mouth consumers, this is, credit-constrained consumers that nonetheless hold positive illiquid housing wealth, and whose nondurable consumption still reacts very strongly to income shocks.

The wealthiest agents in the model may borrow some funds to adjust their optimal decisions through time but they are not credit constrained. In the model wealth above the minimum down payment could be invested in the house or in the liquid asset as agents are indifferent between these two options. These are wealthy agents in a traditional sense. They exhibit low marginal propensities to consume out of transitory income shocks, as standard models of macroeconomic theory predict. They can smoothly adjust their consumption by modifying the level of liquid savings or by taking a line of credit using their home equity.

Some parameterizations of the model (results not shown) can generate traditional hand-to-mouth consumers. These are very poor households with zero net wealth who borrow funds against future labor income and spend 
all their income renting a small apartment and consuming the rest in nondurables.

In summary, Figure 1 shows how important the housing decision is for most households, and how it can break the nondurable consumption monotonicity results most economic models predict.

\subsection{Negative marginal propensities to consume}

Since assets and income are equivalent in the model, we can see in Figure 1 that marginal propensities to consume in nondurable goods are negative around income thresholds that prompt adjustments to a larger housing stock.

This result is consistent with the empirical results found in Gross (2018). Using PSID data from 1999 to 2015, Gross finds that households that have recently moved to a similar-sized or larger house than the one they were living in exhibit negative marginal propensities to consume. See Figure 6 in the Appendix.

An unexpected significant positive income shock can trigger a move from renting into buying a medium size house in the current period, or a move from a medium to a large house, reducing nondurable consumption, and showing behavior consistent with Gross findings. The increase in income provides a chance to become a homeowner or switch to a bigger house in the current period, but only through an increase in savings high enough to put down the minimum down payment on a bigger house. In order to come up with this down payment, agents need to cut consumption in nondurables today, exhibiting negative marginal propensities to consume.

Gross (2018) also finds that households that self-report a higher expectation of moving to a larger house in the next two years, have a higher probability of moving, and have consistently lower and more negative marginal propensities to consume than households not planning to move. See Figure 5 in the Appendix.

\subsection{Implications for aggregate variables}

Given the complexity of solving problems with endogenous credit constraints and non-convexities, in order to include a meaningful discrete housing decision, the model in this paper abstracts from other important households decisions, mainly households' labor decisions.

Even so, it is important to look at the possible connections between the micro-heterogeneity the model delivers and some key macroeconomic 
variables. To do so, let us try to understand what qualitative implications aggregate income shocks can have on housing and nondurable consumption, and on aggregate consumption and savings.

For the credit constrained agents in this economy, a negative income shock would reduce nondurable consumption significantly. In Figure 1, one can think of a transitory negative income shock as a change of position of agents to the left. For transitory or small negative income shocks, it is likely that agents would manage not to downsize their housing stock. If this is the case, the entire reduction in aggregate consumption would be in the form of a fall in nondurable consumption. However, if the shock is larger or more permanent, some of the initial wealthy hand-to-mouth consumers would downsize their housing choices by either moving from a large to a medium house, or from a medium house to a small apartment. In this case, we would then see a big reduction in durable or housing consumption, with the sign of nondurable consumption indeterminate. The households that downsize their housing stock by borrowing less, are effectively increasing their savings, and therefore decreasing aggregate (the sum of housing and nondurable) consumption by more than the fall in income.

The prediction of the model is consistent with Krueger, Mitman, and Perri (2016), who showed that in order to match some key cross sectional and dynamic moments in the data around the Great Recession, any theoretical model should have wealth-poor households that do not behave as handto-mouth consumers, this is, wealth-poor households should increase their saving rate and reduce their expenditure rates strongly as a recession hits.

The historically high home ownership rates and mortgage balances observed before the Great Recession point to a sizable wealthy hand-to-mouth consumer group of the type produced by this model and therefore could help explain why, unlike in previous recessions, the Great Recession was characterized by a fall in both durable and nondurable expenditures.

\subsection{The importance of the set of housing choices}

Figures 2 and 3 show how the housing choices agents consider can affect home ownership rates and the amount of wealthy hand-to-mouth consumers a model can generate.

In Figure 2, I explore the effects of making all housing choices smaller in size and more affordable. I do this by changing uniformly the size of the housing grid from $\{2,4,6\}$ to $\{1,3,5\}^{10}$. As one can see comparing panels (a) and (b) in Figure 2, as expected, smaller housing options can

\footnotetext{
${ }^{10}$ This changes the ratio of the median house value to labor income in the model from a
} 
generate higher home ownership rates, but also different wealthy hand-tomouth agents, some with larger mortgages than others.

Figure 2: Effects of an uniform movement in the housing grid

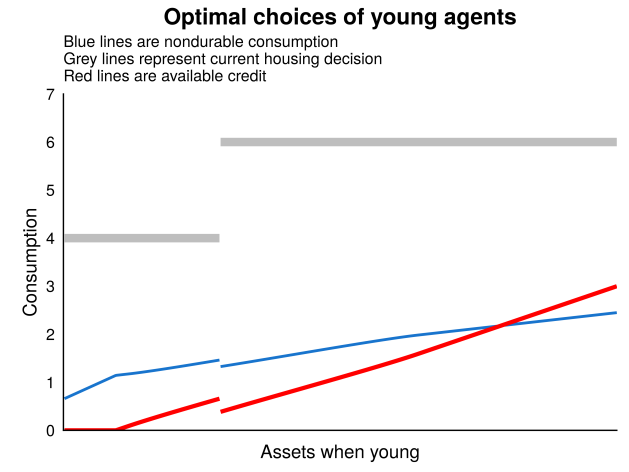

(a) Economy with $h=\{2,4,6\}$

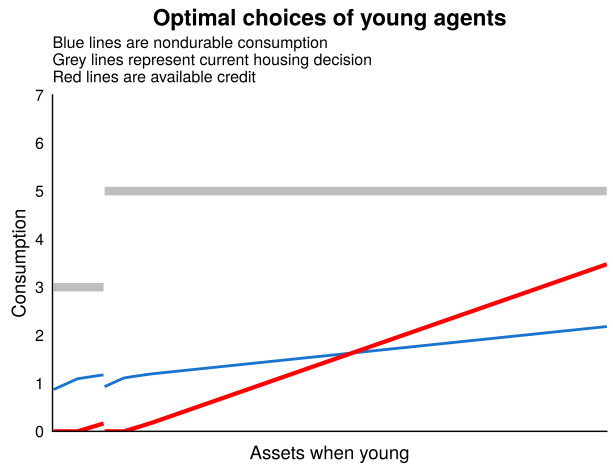

(b) Economy with $h=\{1,3,5\}$

When the houses available for rent are very similar to the houses available for ownership, as shown in panel (a) in Figure 3, some agents prefer renting and home ownership decreases, also reducing the amount of wealthy handto-mouth consumers. At the same time, when differences between medium and large houses are smaller, more agents buy larger houses and borrow more, increasing the amount of wealthy hand-to-mouth consumers the model generates.

More interestingly, the set of housing choices also affects welfare in nontrivial ways. In Figure 4, I graph the lifetime utility of young agents with different initial assets for three economies. The benchmark economy with $h=\{2,4,6\}$, and then another economy with larger differences among housing choices, represented by $h=\{1,4,7\}$, and another one with more similar housing choices, given by $h=\{3,4,5\}$. Surprisingly, in the economy with more homogeneous houses all young agents are better off, independently of their initial assets endownment.

The reason of this finding is that, as one can see in Figure 5, a larger rental, even though more expensive than a smaller one, gives poor agents higher utility while they save in the liquid asset to put a down payment and buy a house later in life. At the same time, it also allows wealthy agents to sell their house later in life and move to an only a bit smaller rental, freeing up their illiquid assets for retirement and giving them flexibility choosing

range of 3.6 to 2.7 to a range of 2.7 to 2 , depending on the measure of labor income used. 
Figure 3: Effects of changes in the dispersion of the housing grid

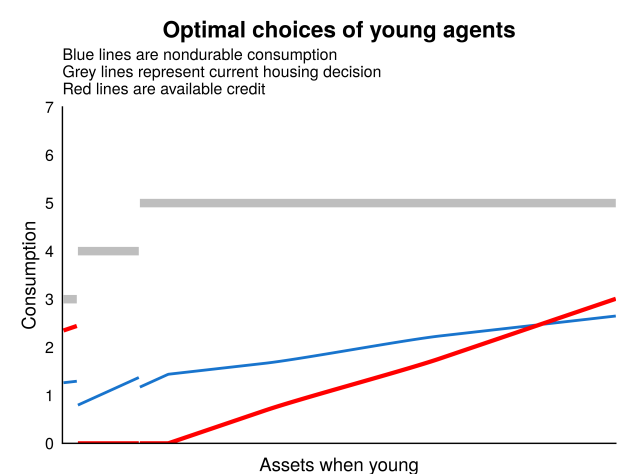

(a) Economy with $h=\{3,4,5\}$

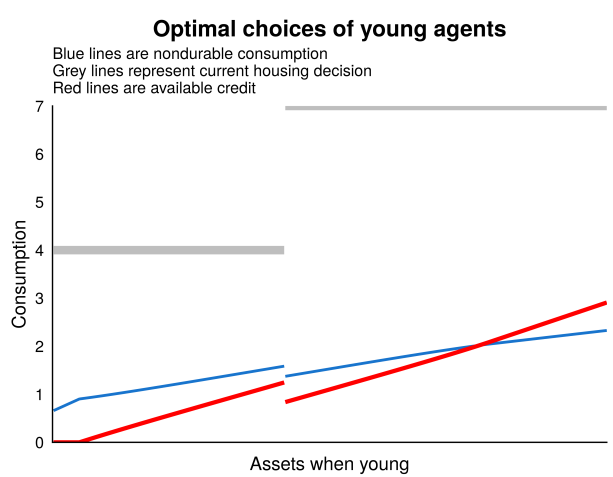

(b) Economy with $h=\{1,4,7\}$

Figure 4: Welfare of young agents under different sets of housing choices

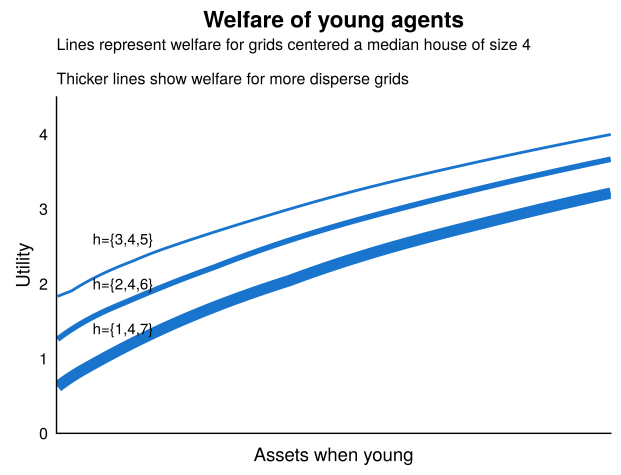

the desired amount of bequest to leave to their offspring. This finding is a consequence of two important assumptions: first, the model does not assume that there are non-pecuniary reasons for being a homeowner, this is, the flow of consumption that agents obtained from a house of size $h$, only depends on the size of the house, and not whether the house is owned or rented. And second, I have not assume that houses are luxury goods, as the available data seems to contradict this assumption. For both reasons, wealthy old agents may still downsize to an attractive rental at the end of their life.

The evolution of non-durable consumption over time (graph not shown) is less interesting, with wealthier agents having higher average and less volatile consumption throughout their life time, and specially early in life, when it is more valued. 
Figure 5: Assets and housing choices over the life cycle when $\{3,4,5\}$

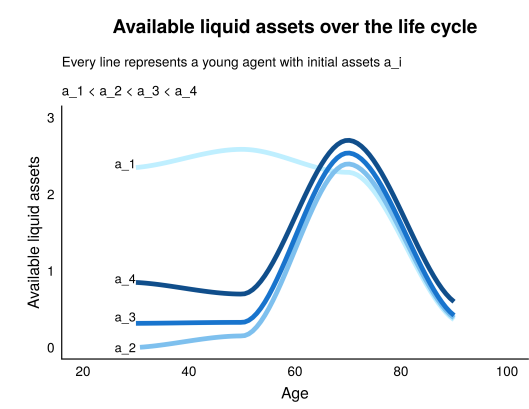

(a) Liquid assets over the life cycle

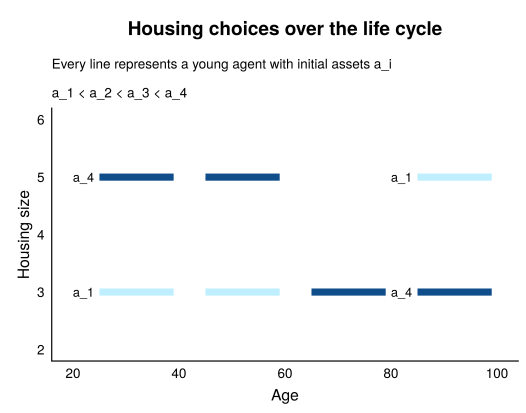

(b) Housing choices over the life cycle

\subsection{Comparative statics}

In order to understand the mechanisms behind the main results of the model, it is useful to do some comparative static exercises changing some key parameters.

The first of such parameters is the discount factor $\beta$. Agents with a higher discount factor who care more about the future and want to save more will also use home ownership as a means of savings, prompting some low wealth agents to cut consumption today to save for the minimum down payment necessary to buy a bigger house early on in life. See panel (a) in Figure 6. Here we have a larger portion of agents credit constrained. Of these agents, some of them live in a medium-sized house and some of them live in a bigger house and hold more illiquid wealth.

Home ownership has become more accessible through time, because of a reduction in selling costs through the use of nontraditional real estate agents and the availability of new mortgages with lower down payment requirements.

As one can see in panel (a) of Figure 7, compared to the benchmark economy, lower selling costs increase home ownership and the amount of wealthy hand-to-mouth consumers generated by the model.

If greater access to home ownership is implemented by requiring a lower down payment when buying a house, the model delivers an increase in home ownership as shown in panel (b) of Figure 7; however the effect on the amount of wealthy hand-to-mouth consumers is ambiguous since credit limits are larger.

Quantitatively, the amount of wealthy hand-to-mouth consumers generated by the model depends on some key variables. For example, as panel (a) 
Figure 6: Effects of heterogeneous discount factors

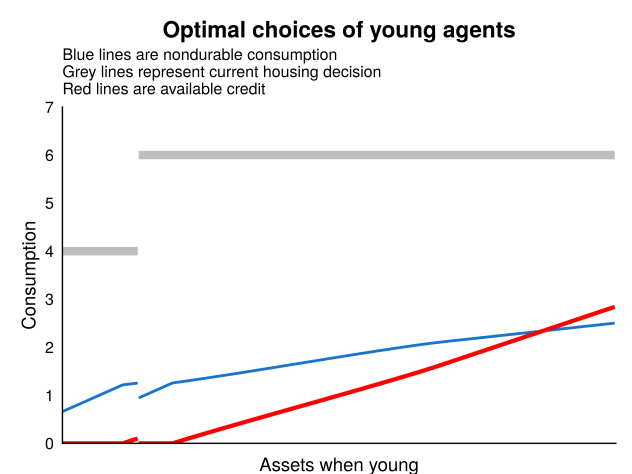

(a) Higher $\beta$

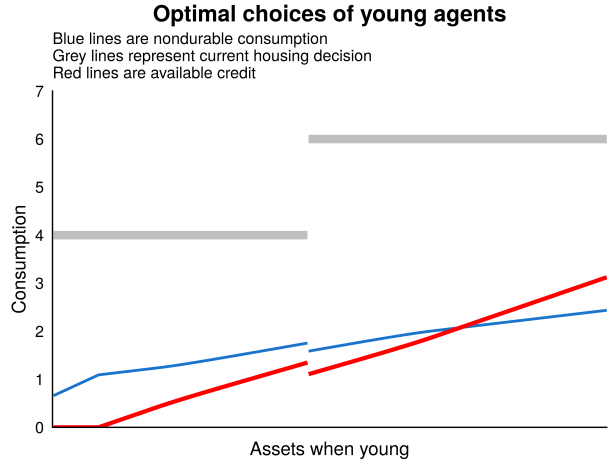

(b) Lower $\beta$

in Figure 8 shows, making the rent option more appealing by making the depreciation rate of rented and owner-occupied houses the same, makes some of these low-wealth agents opt for renting instead of buying and reduces the number of wealthy hand-to-mouth consumers generated by the model. A decrease in the rental price of the small apartment, $p_{r}$, by lowering the relative price of renting versus owning a house, without changing housing characteristics would have the same effect as a decrease in the depreciation rate of the apartment available for rent.

Another important parameter in the model is $\lambda$, the proportion of future income or uncollateralized debt that agents can borrow. When there is less access to debt, as shown in panel (b) in Figure 8 and access is not linked to a house purchase, the change in the amount of wealthy hand-to-mouth consumer generated in the model is ambiguous. On the one hand, some of the low-wealth agents that were buying medium houses before cannot use uncollateralized debt to put the minimum down payment down, and decide to rent and hold liquid wealth, while others agents now are hitting their lower borrowing limit and are credit constrained, holding only illiquid assets.

\section{Conclusions}

This paper has laid down a model to jointly explain the existence of wealthy hand-to-mouth consumers and negative marginal propensities to consume associated with housing upgrades recently found in the data. 
Figure 7: Sensitivity to selling costs and down payment requirements

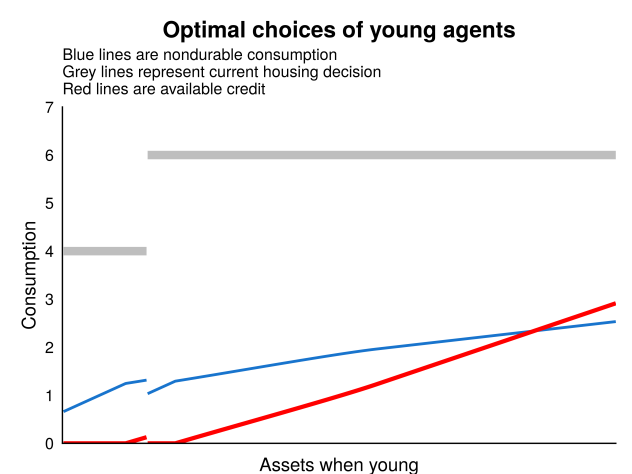

(a) Lower selling costs

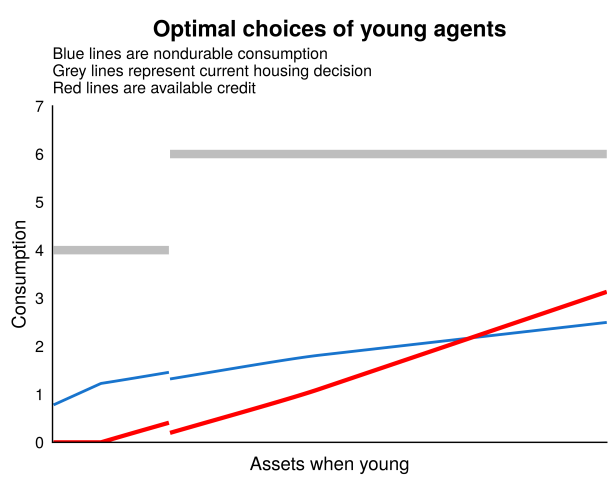

(b) Lower minimum down payment

Moreover, the heterogeneous marginal propensities to consume generated by the model are present under a very general framework, and the reasons why they appear are quite fundamental.

Houses play a dual role in the economy, serving as a saving instrument and providing housing services. They can also act as collateral and are discrete in nature, with significant transaction costs and initial down payments.

In my paper, a model with few housing choices is enough to generate consumers that exhibit negative propensities to consume associated with current or future adjustments in the stock of housing as well as a significant amount of wealthy hand-to-mouth consumers that put down all their wealth into the down payment of a house. This paper highlights the importance of the housing options agents face, and not only of the housing choices they make.

Traditional hand-to-mouth and wealthy hand-to-mouth consumers are similar in some ways but different in other important ways. Hand-to-mouth consumers react strongly to income shocks, but only through changes in nondurable consumption since they are credit constrained, and cannot adjust their savings.

Wealthy hand-to-mouth consumers also react strongly to income shocks, but have two margins to adjust, through changes in non-durable consumption and through changes in their housing choices. Since credit constraints in the model are associated with the stock of housing, by changing their housing choices, agents can also adjust their savings, albeit in an abrupt manner. 
Figure 8: Sensitivity to rental depreciation and uncollateralized debt

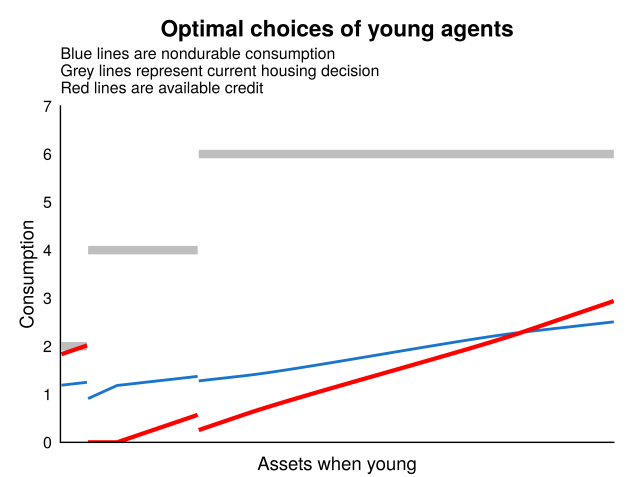

(a) Lower rental depreciation

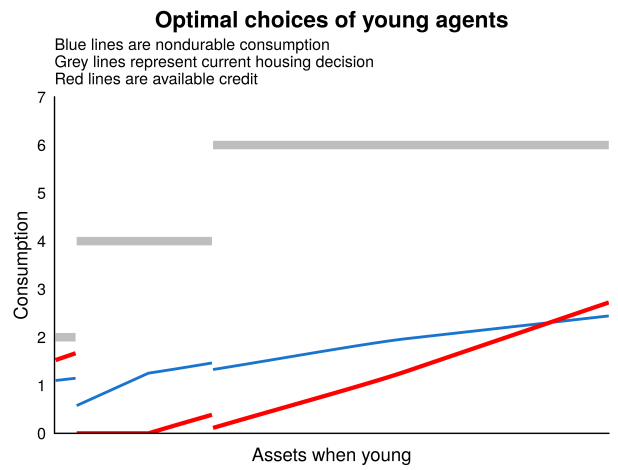

(b) Less uncollateralized debt

Using these mechanisms, the model shows that the behavior of handto-mouth and wealthy hand-to-mouth consumers can affect how aggregate consumption and savings evolve after a shock, or after a fiscal stimulus. Moreover, this type of individual consumption heterogeneity is important for the composition and evolution of aggregate consumption.

In light of the current high levels of home ownership and highly leveraged household, it is important for policy makers to understand how housing related decisions at the individual level interact with consumption and labor dynamics at the aggregate level.

Furthermore, because of the differences between an owner-occupied house and other illiquid assets, the type of wealthy hand-to-mouth consumers generated by this model provides an additional channel to help explain some of the dynamics in the cross-sectional moments found in the data that other models overlook. For example, other models with wealthy hand-to-mouth consumers cannot explain why agents would want to increase precautionary savings in the presence of negative shocks since contributions to illiquid assets such 401K's, college funds or similar are flexible. However, since mortgages payments are fixed at least in the medium term, wealthy hand-tomouth consumers whose illiquid wealth is in a house, may want to increase precautionary savings in times of heightened unemployment risk, just to be able to meet mortgages payments in the future.

The Great Recession in the U.S. was characterized by an average decline in housing price indexes of around $20 \%$, and an increase in the unemployment rate that peaked at $10 \%$ in October of 2009. These simultaneous 
wealth and income shocks to households make microeconomic studies more useful than ever. At the same time, at the macro-level, the challenge of solving a non-convex problem, sophisticated enough to take to the data still remains.

This paper has highlighted the interactions between housing decisions at the micro-level, and the aggregate consumption-savings behavior. The paper's insights are a call to pay attention to the variation in the marginal propensity to consume across agents, to effectively design policies that have the desired effects on economic activity.

After the Great Recession, countries such as Australia, Canada, the U.S., and the U.K., implemented different policies subsidizing access to credit, providing different tax treatment for homeowners, or giving direct transfers to home buyers. This model suggests that we should rethink how these policies contributed to stabilizing housing markets and stimulating aggregate demand.

Since adjusting the housing stock is very costly, future research should examine how an agent's housing status affects their labor markets decisions in the presence of aggregate shocks.

And lastly, by looking at the qualitative welfare analysis developed in this paper, perhaps public policy should focus on promoting greater availability of better rentals in areas or neighborhoods where the only housing options available are houses to buy. 


\section{References}

[1] Attanasio, O. P., Bottazzi, R., Low, H. W., Nesheim, L., and Wakefield, M. (2012): Modelling the Demand for Housing over the Life Cycle, Review of Economic Dynamics, 15, 1-18.

[2] Bajari, P., P. Chan, D. Krueger, and D. Miller (2013): A Dynamic Model of Housing Demand: Estimation and Policy Implications, International Economic Review, 54, 409-442.

[3] Campbell, J.R., and Hercowitz, Z. (2018): Liquidity Constraints of the Middle Class, CentER Discussion Paper Series No. 2018-039

[4] Chambers, M., Garriga, C., and Schlagenhauf, D.E.(2009a): Accounting for Changes in the Home Ownership Rate, International Economic Review 50(3):677-726 .

[5] Chambers, M., Garriga, C., and Schlagenhauf, D.E.(2009b): Housing policy and the progressivity of income taxation, Journal of Monetary Economics, November 2009, Vol. 56, No. 8, pp. 1116-34.

[6] Davis, M.A., and Heathcote, J. (2005): Housing and the business cycle, International Economic Review Vol. 46, No. 3, August 2005.

[7] Fella, G. (2014): A generalized endogenous grid method for non-smooth and non-concave problems, Working Paper.

[8] Greenwood, J., and Hercowitz, Z. (1991): The Allocation of Capital and Time over the Business Cycle, Journal of Political Economy, University of Chicago Press, vol. 99(6), pages 1188-1214.

[9] Gross, I. Working Paper (2018): Anticipated changes in household debt and consumption.

[10] Gruber, J. and Martin, R. (2003): Precautionary savings and the wealth distribution with illiquid durables, International Finance Discussion Papers No. 773, Board of Governors of the Federal Reserve System.

[11] Hatchondo, J.C., Martinez, L., and Sanchez, J.M. (2015): Mortgage defaults, Journal of Monetary Economics 76, 173190.

[12] Iacoviello, M. and Pavan, M. (2013): Housing and Debt over the Life Cycle and over the Business Cycle. Journal of Monetary Economics, 60, 221-238. 
[13] Kaplan, G., and Violante, G.L. (2014): A Model of the Consumption Response to Fiscal Stimulus Payments, Econometrica Volume 82, Issue 4, 1199-1239.

[14] Kaplan, G., and Violante, G.L. (2010): How much consumption insurance beyond self-insurance? American Economic Journal: Macroeconomics $2(4), 53-87$.

[15] Kaplan, G., Mittman, K., and Violante, G.L. (2016): Non-durable Consumption and Housing Net Worth in the Great Recession: Evidence from Easily Accessible Data, NBER Working Paper No. 22232.

[16] Krueger, D., Mitman, K., and Perri, F. (2016): Macroeconomics and Household Heterogeneity, Handbook of Macroeconomics.

[17] Krusell, P., and Smith, A.A.Jr. (1998): Income and Wealth Heterogeneity in the Macroeconomy, Journal of Political Economy, Volume 106, No.5.

[18] Martin, R.F. (2003): Consumption, Durable Goods, and Transaction Costs, FRB International Finance Discussion Paper No. 756.

[19] Mian, A., Rao, K., and Sufi, A. (2013): Household Balance Sheets, Consumption, and the Economic Slump, Quarterly Journal of Economics $128.4,1687-1726$.

[20] Misra, K., and Surico, P. (2011): Heterogeneous Responses and Aggregate Impact of the 2001 Income Tax Rebates, Discussion Paper 8306, CEPR.

[21] Parker, J.A., Souleles, N.S., Johnson, D.S., and McClelland, R. (2013): Consumer Spending and the Economic Stimulus Payments of 2008, American Economic Review, American Economic Association, vol. 103(6), pages 2530-255.

[22] Pizzinelli, C. Working Paper (2017): Housing borrowing constraints, and labor supply over the life cycle.

[23] Rios-Rull, J.V. and Sanchez-Marcos, V. (2008): An aggregate economy with different size houses, Journal of the European Economic Association, Volume 6, Issue 2-3, Pages 705714. 


\section{Appendix}

\subsection{Evidence on negative marginal propensities to consume}

Martin (2003) studied a model of consumption of durable and nondurable goods where the durable good was subject to transaction costs. He found that the transaction cost could induce an inaction region in the purchase of the durable good that provoked variation in consumption of the nondurable good over this region. In his model, this variation is a function of the degree of complementarity between durable and nondurable goods in the period utility function, the rate of intertemporal substitution, and a precautionary motive induced by incomplete markets. He then tested the model using PSID data, taking housing as the durable good and food as the nondurable good. He pointed out that data indicate an increase in food consumption before moving to a smaller house and a decrease in food consumption before moving to a larger house.

Adding to Martin's paper and using a biannual sub-sample PSID data from 1999 to 2015, Gross (2018) created a broader measure of consumption that includes food, utilities, gasoline, car repairs, and other services. Following Kaplan and Violante (2010), Gross cleans the consumption and income data by regressing the log of those variables on year, cohort, and other demographic variables.

After that, and in order to compute marginal propensities to consume, Gross places households into groups following three different strategies. First, he groups households planning to adjust their housing stock in the next two years by their self-reported answer to a related PSID question. Second, he groups households by the likelihood that they will move estimated using a logit model regressing decisions to move on lagged expectations. Third, he groups households by their actual moves in the following two years, and whether they moved to a smaller, same-sized, or bigger house than the one the previously lived in. Finally, he estimates the marginal propensities to consume out of income for each of the three strategies finding negative marginal propensities to consume associated with planned or actual upgrades in the stock of housing.

The three strategies convey the same message-that is, most of the upgrades in the housing stock are planned, and are associated with decreases in nondurable consumption before and immediately after the adjustment. The results for the first two strategies are shown in Figure 5 in his paper, and the results for the third strategy are shown in Figure 6. Both figures copied here. 

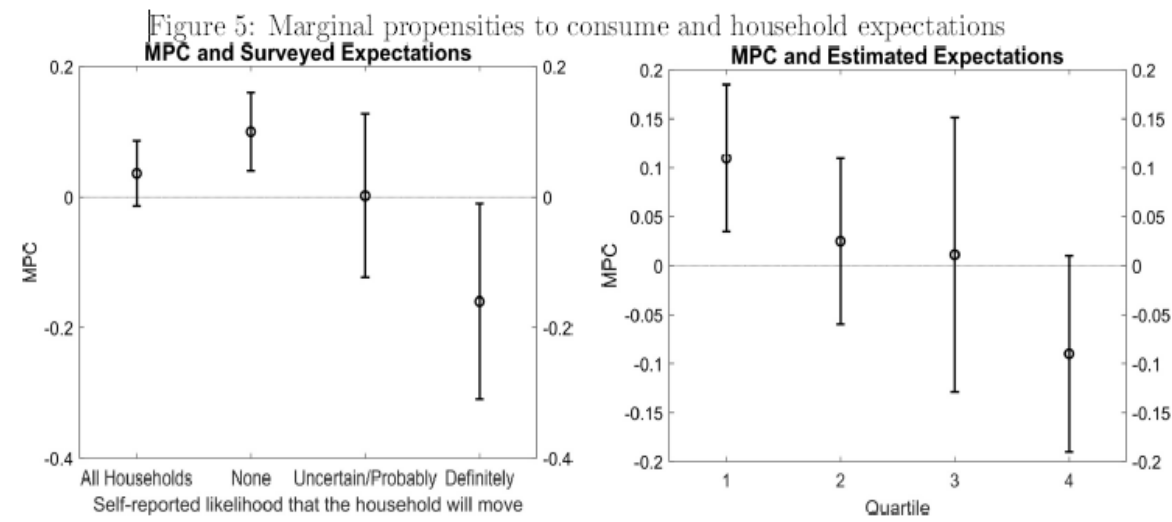

Figure 5: Gross (2018), PSID survey data from 1999 to 2015.

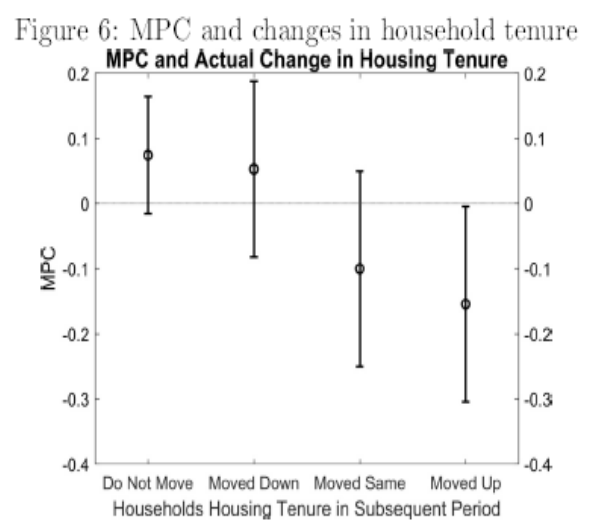

Figure 6: Gross (2018), PSID survey data from 1999 to 2015. 